\section{Comparative Analysis of the Proteomic Profile of the Dental Pulp in Different Conditions. A Pilot Study}

Caroline Loureiro ${ }^{1} \mathbb{D}$, Marilia Afonso Rabelo Buzalaf ${ }^{2} \mathbb{D}^{\mathbb{D}}$, Juliano Pelim Pessan ${ }^{1}$ (D),

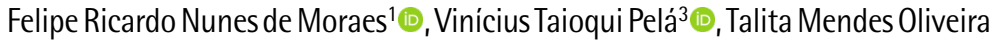
Ventura $^{2}{ }^{D}$, Rogério de Castilho Jacinto ${ }^{1}$ (D)

\begin{abstract}
This study aimed to quantitatively compare the difference in protein expression in the progression of pulp pathogenesis, as well as to describe the biological functions of proteins identified in pulp tissue. Samples were obtained from six patients treated at the Araçatuba School of Dentistry and were divided into three groups: normal pulp - from teeth extracted for orthodontic indication; inflamed pulp and necrotic pulp - from patients diagnosed with irreversible pulpitis and chronic apical periodontitis, respectively. After previous proteomic preparation, dental pulp samples were processed for label-free quantitative proteomic analysis in a nanoACOUITY UPLC-Xevo OTof MS system. The difference in expression between the groups was calculated using the Protein Lynx Global Service software using the Monte Carlo algorithm. A total of 465 human proteins were identified in all groups. The most expressed proteins in the inflamed pulp group in relation to the normal pulp group were hemoglobin, peroxiredoxins and immunoglobulins, whereas the less expressed were the tubulins. Expression levels of albumins, immunoglobulins and alpha-2-macroglobulin were higher in the necrotic pulp group than in the inflamed pulp group. As for the qualitative analysis, the most prevalent protein functions in the normal pulp group were metabolic and energetic pathways; in the inflamed pulp group: cellular communication and signal transduction; and regulation and repair of DNA/RNA, while in the necrotic pulp group proteins were associated with the immune response. Thus, proteomic analysis showed quantitative and qualitative differences in protein expression in different types of pulp conditions.
\end{abstract}

'Department of Preventive and Restorative Dentistry, Araçatuba School of Dentistry, UNESP Universidade Estadual Paulista, Araçatuba, SP, Brazil ${ }^{2}$ Department of Biological Sciences, Bauru School of Dentistry, USP - Universidade de São Paulo, Bauru, SP, Brazil ${ }^{3}$ Department of Genetics and Evolution, UFSCar Universidade Federal de São Carlos, São Carlos, SP, Brazil

Correspondence: Prof. Rogério de Castilho Jacinto, Rua José Bonifácio, 1193, 16015-050 Araçatuba, SP, Brasil. Tel: +55-18-3636-3278. e-mail: rogerio.castilho@unesp.br

Key Words: proteomic analysis, dental pulp, pulpitis, dental pulp necrosis, endodontics.

\section{Introduction}

Dental pulp is a complex specialized tissue with nourishing, restorative, sensorial and defensive functions (inflammatory or degenerative defenses, depending on the characteristics of the irritant). Although several etiological factors can cause pulp damage, the biological factor, represented by polymicrobial communities usually organized as biofilm, is the most relevant (1). The characteristic events of the inflammatory process, such as the recruitment of defense cells from the innate and adaptive immune response, and the presence of chemical mediators alter the physiology of the dental pulp in the attempt to remove the aggressive agent. Damage to the pulp tissue can occur in the persistence of the irritant agent, destructuring the tissue and leading to a process of necrosis. In this context, bacteria colonize the root canal system and start releasing potential antigens into the periapical tissues, thus triggering the development of apical diseases $(2,3)$.

Proteomic analysis is the study of the whole set of proteins expressed by an organism in a particular environment during a specific stage of the cell cycle. It also covers their relative abundance, distribution, functions and interaction with other macromolecules (4). This approach has also been widely applied in medical microbiology, collecting information related to bacterial resistance and virulence, which has been used in the development of new diagnostic and therapeutic applications for the treatment of infectious diseases (5). Therefore, proteomic techniques are important tools for investigating the progression of both pulp alterations and study of the host / pathogen response to infections (6).

Characterization and expression of proteins using liquid chromatography (LC) / mass spectrometry (MS / MS) has gained prominence in proteomic analysis of pulp tissue, since this method provides the necessary technology for the study of small amounts of samples from complex biological systems (7). This method involves the proteolytic digestion of all proteins in the samples and their subsequent identification using a database of individual peptides, reducing sample handling time and eliminating the need for individual protein processing (8). The direct identification of proteins expressed in pulp and periapical diseases, involving descriptive analysis of pulp pathogenesis, focusing on: 
primary and persistent infections (9); endodontic abscesses (10); and cases of failure of endodontic treatment (11) has allowed the identification of several human proteins, which were mainly related to cellular processes, metabolism and immune defense.

Although the above-mentioned studies provided significant contribution to the comprehension of endodontic infections, they employed qualitative identification approaches, which do not allow a direct quantitative comparison of the expression of proteins of human origin. Furthermore, to date no study has assessed the proteomic profile of the human pulp tissue with different degrees of microbial injury, especially determining quantitatively the down- and up-regulated proteins. Therefore, considering the scarcity of proteomic studies of pulp diseases, this pilot study aimed to compare the protein profile at different clinical stages during the progression of pulp diseases, as well as to describe the biological functions of each protein detected in the samples within the different pulp conditions (normal, inflamed or necrotic pulp tissue).

\section{Material and Methods}

\section{Patient Selection}

All patients signed an informed consent form prepared in accordance with the rules of the Research Ethics Committee of the Araçatuba School of Dentistry - UNESP ( No 91331518.7.0000.5420). Samples were taken from patients with no history of systemic diseases, who attended the Endodontic Clinic of the Araçatuba School of Dentistry - UNESP for root canal treatment, and were divided into three groups: normal pulp group with pulp tissue samples obtained from teeth extracted for orthodontic indication $(n=2)$; inflamed pulp group - samples obtained from patients diagnosed with irreversible pulpitis $(n=2)$, and necrotic pulp group - samples obtained from patients diagnosed with chronic apical periodontitis $(n=2)$. Clinical and radiographic characteristics and a detailed anamnesis of the patient's health conditions were recorded (Table 1).

\section{Sample Collection}

The collection was done aseptically. Firstly, the crown of the tooth to be sampled was cleaned with pumice paste and water, followed by removal of the restoration and/ or carious tissue without exposing the root canals. Then, the tooth was individually isolated from the oral cavity with a rubber dam, except for the normal pulp sample. The tooth and the surrounding field were cleaned with $30 \%$ hydrogen peroxide and decontaminated with $2.5 \%$ sodium hypochlorite solution for $30 \mathrm{~s}$ each, followed by neutralization of the solution with 5\% sodium thiosulfate (3). The access to the pulp cavity was performed with sterile carbide bur without water spray. Irrigation during the access phase was done with sterile saline solution.

Normal pulp - To obtain the normal pulp sample, teeth with healthy pulp and without periodontal disease, indicated for orthodontic extraction, were selected. Immediately after the extraction, the pulp tissue was carefully removed with the aid of sterile manual files (Hedstroem file size \#20, Dentsply Sirona, Ballaigues, Switzerland), avoiding contamination and complete disruption of the pulp tissue.

Inflamed pulp - In cases of irreversible pulpitis, consistent pulp tissue was collected from the palatal or distal canal with Hedstroem file, complemented by three sterile paper points introduced into the apparent length of the canal determined on diagnostic radiographs, and held in place for $60 \mathrm{~s}$ each, without any irrigation.

Necrotic pulp - Samples of the teeth with pulp necrosis, with radiographic lesion (chronic apical periodontitis), were obtained immediately after exposure of the pulp chamber. A sterile K-type file was introduced with minimal instrumentation, without the use of any irrigant to disrupt biofilms of the canal wall; then three sterile paper points were introduced into the apparent length of the canal determined on diagnostic radiographs and held in place for $60 \mathrm{~s}$ each. If the canal was completely dry, a drop of sterile saline was placed before removing the paper point. In cases of teeth with more than one canal, the sample was

Table 1. Clinical and radiographic characteristics of patients included in each group

\begin{tabular}{|c|c|c|c|c|c|}
\hline Groups & Gender & Tooth & Thermal stimuli & Radiographic examination & Clinical characteristics \\
\hline \multirow[b]{2}{*}{ Normal pulp } & Female & 15 & Positive (normal) & \multirow{2}{*}{$\begin{array}{l}\text { Normal radiographic bone level } \\
\text { with intact lamina dura and } \\
\text { complete root formation }\end{array}$} & \multirow{2}{*}{$\begin{array}{l}\text { Absence of carious lesion } \\
\text { or symptomatology and } \\
\text { normal probing depth }\end{array}$} \\
\hline & Male & 34 & Positive (normal) & & \\
\hline \multirow{2}{*}{ Inflamed pulp } & Male & 36 & Positive (acute) & \multirow{2}{*}{$\begin{array}{l}\text { There was no periodontal ligament } \\
\text { widening or periapical radiolucency } \\
\text { and complete root formation }\end{array}$} & \multirow{2}{*}{$\begin{array}{l}\text { Carious lesion without pulp } \\
\text { exposure, spontaneous pain } \\
\text { and normal probing depth }\end{array}$} \\
\hline & Female & 16 & Positive (acute) & & \\
\hline \multirow{2}{*}{ Necrotic pulp } & Female & 46 & Negative & $\begin{array}{l}\text { Periapical radiolucency on the } \\
\text { mesial and distal roots }\end{array}$ & \multirow{2}{*}{$\begin{array}{l}\text { Extensive restoration with caries } \\
\text { recurrence, absence of symptoms } \\
\text { and normal probing depth }\end{array}$} \\
\hline & Female & 26 & Negative & $\begin{array}{c}\text { Extensive periapical radiolucency } \\
\text { on the palatal root }\end{array}$ & \\
\hline
\end{tabular}


collected only from the widest canal, since it was associated with the apical lesion (otherwise the tooth would not be included in the study), to confine the analysis to a single environment.

After the collection, the paper points and tissue samples were placed in sterile, DNA-free and RNA-free cryotubes, which were frozen at $-80^{\circ} \mathrm{C}$ until use for proteomic analysis.

\section{Proteomic Analysis - Preparation of Pulp Samples}

The paper points were cut and samples corresponding to the same groups were pooled. In the tubes containing the paper points an extraction solution containing $6 \mathrm{M}$ urea, $2 \mathrm{M}$ thiourea in $50 \mathrm{mM} \mathrm{NH}_{4} \mathrm{HCO}_{3} \mathrm{pH} 7.8$ was added until the papers were covered. The samples were then vortexed for $10 \mathrm{~min}$ at $4{ }^{\circ} \mathrm{C}$, followed by sonication for 5 min and centrifugation at $20,817 \times g$ for 10 min at $4{ }^{\circ} \mathrm{C}$. The supernatant was collected, and this procedure was repeated once more. The papers were placed in filter tubes (Corning ${ }^{\circledR}$ Costar $^{\circledR}$ Spin- $X{ }^{\circledR}$ Plastic Centrifuge Tube Filters Sigma-Aldrich, New York, USA) and centrifuged at 20,817 $\times g$ for 10 min at $4{ }^{\circ} \mathrm{C}$. The supernatant was collected and added to the previously collected supernatant. Soon after, $1.5 \mathrm{~mL}$ of $50 \mathrm{mM} \mathrm{NH}_{4} \mathrm{HCO}_{3}$ was added to the samples. The samples were then placed in Falcon Amicon Ultra-4 10k tubes (Merck Millipore, Ireland) and centrifuged at 4,500 $\times g$ at $4^{\circ} \mathrm{C}$ to approximately $150 \mu \mathrm{L}$.

Then, $5 \mathrm{mM}$ dithiothreitol (DTT) was added to the samples and they were incubated at $37^{\circ} \mathrm{C}$ for $40 \mathrm{~min}$. After this time, $10 \mathrm{mM}$ iodoacetamide (IAA) was added and the samples were incubated for $30 \mathrm{~min}$ in the dark. After the incubations, $100 \mu \mathrm{L}$ of $50 \mathrm{mM} \mathrm{NH}{ }_{4} \mathrm{HCO}_{3}$ were added and shortly thereafter the tryptic digestion was performed for $14 \mathrm{~h}$ at $37^{\circ} \mathrm{C}$ by the addition of $2 \%(\mathrm{w} / \mathrm{w}$ ) trypsin (Promega, Madison, USA). After the digestion, 5\% formic acid was added to stop the action of trypsin and the procedures were performed with the C18 spin column (Thermo Scientific, United States) for desalting and purifying the samples. Thus, an aliquot of each sample $(1 \mu \mathrm{L})$ was removed and protein quantification was performed by the Bradford method (Bio-Rad Bradford Assays). The remnants were dried to approximately $1 \mu \mathrm{L}$ in SpeedVac (Thermo Scientific, United States). After drying the samples were resuspended in 3\% acetonitrile and $0.1 \%$ formic acid for the application to the nano Liquid Chromatography Electron Spray Ionization Tandem Mass Spectrometer (nLC-ESI-MS / MS) (12).

\section{Shotgun Label-Free Quantitative Proteomic Analysis}

Peptidesidentification was performed on a nanoACQUITY UPLC-Xevo OTof MS system (Waters, Manchester, New Hampshire, UK). The nanoACOUITY UPLC was equipped with nanoACQUITY HSS T3, analytical reverse phase column (75 $\mu \mathrm{m} X 150 \mathrm{~mm}, 1.8 \mu \mathrm{m}$ particle size (Waters, Manchester, New
Hampshire, UK). The column was equilibrated with mobile phase $A(0.1 \%$ formic acid in water). Then, the peptides were separated with a linear gradient of 7-85\% mobile phase B ( $0.1 \%$ formic acid in $\mathrm{ACN})$ for $70 \mathrm{~min}$ at a flow rate of $0.35 \mu \mathrm{L} / \mathrm{min}$. The column temperature was maintained at 55 ${ }^{\circ} \mathrm{C}$. The Xevo G2 Q-TOF mass spectrometer was operated in positive nanoelectrospray ion mode and data were collected using the MSE method in elevated energy (19-45 V), which allows data acquisition of both precursor and fragment ions, in one injection. Source conditions used included capillary voltage, $2.5 \mathrm{kV}$; sample cone, $30 \mathrm{~V}$; extraction cone, $5.0 \mathrm{~V}$ and source temperature, $80{ }^{\circ} \mathrm{C}$. Data acquisition occurred over $70 \mathrm{~min}$ and the scan range was 50-2000 Da. The lock spray, used to ensure accuracy and reproducibility, was run with a [Glu1] fibrinopeptide solution $(1 \mathrm{pmol} / \mu \mathrm{L})$ at a flow rate of $1 \mu \mathrm{L} / \mathrm{min}$, as a reference ion in positive mode at $\mathrm{m} / \mathrm{z}$ 785.8427. ProteinLynx Global Server (PLGS) version 3.0 was used to process and search the LC-MSE continuum data. Proteins were identified with the embedded ion accounting algorithm in the software and a search of the Homo sapiens database (UniProtKB/Swiss-Prot) downloaded on April 2017 from UniProtKB (http://www.uniprot.org/).

For label-free quantitative proteome, three MS raw files from normal, inflamed and necrotic pulp groups were analyzed using the Protein Lynx Global Service (PLGS, v 2.2.5, Waters Co., Manchester, UK) software. All the proteins identified with a score with confidence greater than that 95\% were included in the quantitative statistical analysis embedded in the PLGS software. Identical peptides from each triplicate by sample were grouped based on mass accuracy $(<10 \mathrm{ppm})$ and on time of retention tolerance $<0.25 \mathrm{~min}$, using the clustering software embedded in the PLGS. Difference in expression among the normal and inflamed pulp groups and inflamed and necrotic groups was calculated using Monte-Carlo algorithm and expressed as $p<0.05$ for proteins present in lower abundance and $1-p>0.95$ for proteins present in higher abundance.

In the quantitative analysis, two comparisons were made among the groups: The first comparison was between the normal and inflamed pulp groups, and the second was between the inflamed and necrotic pulp groups. Proteins expressed at a ratio $>2.0$ in relation to the group of comparison were regarded as up-regulated, while proteins expressed at a ratio $<0.5$ were regarded as down-regulated proteins. Proteins expressed with ratio between 0.5 and 2 were disregarded. The identified proteins were classified according to their biological functions using Homo sapiens database (UniProtKB/Swiss-Prot).

\section{Results}

Overall, 465 proteins were identified from the samples in all groups. Among them, 30 were common to all groups, 
including six isoforms of Actin, Albumin, Alpha-1_4 glucan phosphorylase, three isoforms of Glycogen and six isoforms of Hemoglobin, Serum albumin, among other proteins such as Apolipoprotein A-II, Haptoglobin and three isoforms of Immunoglobulin (Fig. 1).

The proteins expression were divided into 12 categories: metabolism and energy pathways, immune response, transport, structure, DNA/RNA regulation and repair, cell communication and signal transduction, cell growth and/ or maintenance, differentiation of neural cells, apoptosis, stress response, ions regulation and binding and proteins of unknown function (8) (Tables 2 and 3).

When comparing the inflamed pulp group with the normal pulp group, 39 proteins were found at higher levels in the first, among which 18 had more than a 2-fold increase, e.g. 4 subunits of Hemoglobin (100-fold higher), 2 isoforms of Peroxiredoxin, (20-fold higher), 3 isoforms of Immunoglobulin (10-fold higher), Glyceraldehyde-3phosphate dehydrogenase (2-fold higher). On the other hand, 41 proteins were found at lower levels in inflamed pulp group in comparison with normal pulp group, among which 17 were isoforms of Tubulin, besides other cytoskeletal proteins, such as Desmin. Serum albumin and neurofilament proteins, such as Alpha-internexin, Neurofilament medium polypeptide were also reduced (Table 2).

When necrotic pulp group was compared with inflamed pulp group, 8 proteins were found at higher levels and 26 at lower levels in the necrotic pulp group. Among the high level proteins, 8 of them were more than 2-fold higher (2 isoforms of Serum albumin, Immunoglobulin heavy constant gamma 1 and Alpha-2-macroglobulin). As for the low level proteins, 13 were more than 2-fold

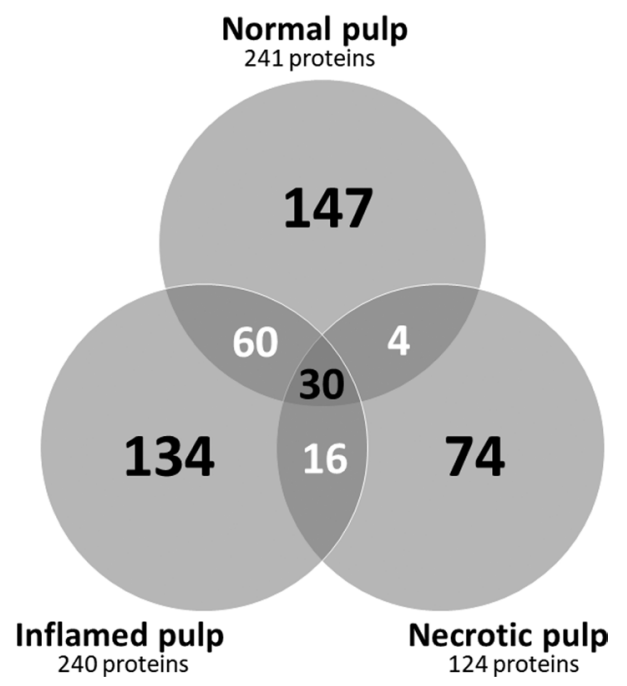

Figure 1. Venn diagram of proteins identified in all groups and the relation between them. lower (various isoforms of Hemoglobin, various isoforms of POTE ankyrin domain, various isoforms of Actin and Bromodomain-containing protein 3 ) (Table 2).

Table 3 shows the proteins exclusively identified in each one of the groups. Most of the proteins identified in the normal pulp group were involved in metabolic and energy pathways (20.4\%) and in cell communication and signal transduction (20.4\%). While in the inflamed pulp group, the cellular communication and signal transduction function $(19.4 \%)$ also presented a higher percentage, followed by regulation and repair of DNA / RNA (17.9\%). Finally, in the necrotic pulp group, most proteins were involved in the immune response (24.3\%). (Fig. 2).

Alpha-2-macroglobulin, Transthyretin and Apolipoprotein A-I were not identified in the normal pulp group, while Beta-actin-like protein 2 was not found in necrotic pulp group. Isoforms of Neutrophil defensin were not found in the groups of normal and inflamed pulp, while Serotransferrin was identified in the groups of normal and necrotic pulp.

\section{Discussion}

Proteomic techniques have helped to improve the knowledge of the biology, function and pathology of the pulpal tissues. Tissue formation, diagnosis, identification of risk factors, tissue engineering and pathogenesis of endodontic infections represent some of the most important themes investigated in proteomic studies of the pulp. The understanding of proteins and their functions provide insights into the complex host-pathogen relationship and host antimicrobial strategies to combat infections (13). To our knowledge, this pilot study is the first to describe and quantify the proteome of the pulp tissue in relation to the progression of pulp diseases, comparing the protein profile of different pulp diagnoses and their relationship with the characteristic events of each diagnosis. The nLC-ESI-MS/ MS method allowed the identification of 465 different proteins. The high sensitivity of the method makes it possible to identify and comparatively quantify proteins in tiny amounts of samples, such as samples for root canals, allowing the study of its pathological processes (14).

In order comprehend the mechanisms related to the host in relation to the progression of the pulp disease, two comparisons were made between the groups. The first comparison (normal vs inflamed tissue) showed a significant up-regulation of 4 subunits of Hemoglobin. Approximately one third of the mass of a human red blood cell (RBCs) is hemoglobin (15). RBCs participate in the vascular system and its increase is related to the diagnosis of the pulp. The inflammation of the dental pulp causes an immediate increase in blood flow, along with vasodilation, increased blood supply and microcirculation (16). 
Table 2. Human proteins that were more than 2-fold higher or lower in inflamed (I) compared with normal (NO) pulp group and necrotic (NE) compared with inflamed (I) pulp group

\begin{tabular}{|c|c|c|c|c|}
\hline Accession & Description & Biologic process & Score & Ratio I:NO \\
\hline P68871 & Hemoglobin subunit beta ${ }^{\mathrm{C}}$ & Oxygen transport & 25560 & 262.43 \\
\hline P02042 & Hemoglobin subunit delta ${ }^{\mathrm{C}}$ & Oxygen transport & 6892 & 164.02 \\
\hline G3V1N2 & HCG1745306_isoform CRA_a ${ }^{c}$ & Oxygen transport & 6068 & 139.77 \\
\hline P69905 & Hemoglobin subunit alpha ${ }^{\mathrm{C}}$ & Oxygen transport & 16796 & 139.77 \\
\hline Q14980 & Nuclear mitotic apparatus protein ${ }^{\mathrm{F}}$ & Cell division & 282 & 29.96 \\
\hline P32119 & Peroxiredoxin- $2^{\mathrm{F}}$ & Cell redox homeostasis & 558 & 24.05 \\
\hline Q06830 & Peroxiredoxin-1 $\mathrm{F}$ & Cell redox homeostasis & 558 & 22.20 \\
\hline P01876 & Immunoglobulin heavy constant alpha $1^{\mathrm{B}}$ & Adaptive immunity & 338 & 14.44 \\
\hline P02652 & Apolipoprotein A-II ${ }^{\mathrm{C}}$ & Transport & 1124 & 12.94 \\
\hline P01877 & Immunoglobulin heavy constant alpha $2^{\mathrm{B}}$ & Adaptive immunity & 338 & 12.81 \\
\hline P00738 & Haptoglobin ${ }^{B}$ & Acute phase. Immunity & 842 & 11.94 \\
\hline P01857 & Immunoglobulin heavy constant gamma $1^{\mathrm{B}}$ & Adaptative immunity & 822 & 11.70 \\
\hline Q9Y2L5 & $\begin{array}{l}\text { Trafficking protein particle } \\
\text { complex subunit } 8^{\mathrm{C}}\end{array}$ & Transport & 426 & 9.39 \\
\hline Q7Z2K6 & Endoplasmic reticulum metallopeptidase $1^{\mathrm{A}}$ & Catalytic activity & 573 & 6.05 \\
\hline P60174 & Triosephosphate isomerase ${ }^{\mathrm{A}}$ & Glycolysis & 216 & 3.19 \\
\hline Q9Y4G6 & Talin-2 ${ }^{\mathrm{D}}$ & Structural constituent of cytoskeleton & 333 & 2.48 \\
\hline P04406 & $\begin{array}{c}\text { Glyceraldehyde-3-phosphate } \\
\text { dehydrogenase }\end{array}$ & Oxidoreductase & 312 & 2.23 \\
\hline Q562R1 & Beta-actin-like protein $2^{\mathrm{D}}$ & Structural constituent of cytoskeleton & 2959 & 0.44 \\
\hline P17661 & Desmin $^{D}$ & Cytoskeleton organization & 4264 & 0.39 \\
\hline Q8TAI7 & GTPase RhebL1 ${ }^{\mathrm{F}}$ & Transcription factor activity & 277 & 0.39 \\
\hline Q16352 & Alpha-internexin ${ }^{\mathrm{H}}$ & Differentiation. Neurogenesis & 3973 & 0.38 \\
\hline P07197 & Neurofilament medium polypeptide ${ }^{\mathrm{D}}$ & Structural constituent of cytoskeleton & 3973 & 0.38 \\
\hline Q9BY44 & Eukaryotic translation initiation factor $2 \mathrm{~A}^{\mathrm{D}}$ & Translation regulation & 444 & 0.36 \\
\hline Q9BUF5 & Tubulin beta- 6 chain ${ }^{D}$ & Microtubule-based process & 5168 & 0.35 \\
\hline A6NNZ2 & $\begin{array}{l}\text { Tubulin beta-8 chain-like } \\
\text { protein LOC } 260334^{\text {D }}\end{array}$ & Microtubule-based process & 5281 & 0.34 \\
\hline P02768 & Serum albumin ${ }^{\mathrm{C}}$ & Transport & 14783 & 0.32 \\
\hline P68371 & Tubulin beta-4B chain ${ }^{D}$ & Microtubule-based process & 23514 & 0.32 \\
\hline P04350 & Tubulin beta-4A chain ${ }^{D}$ & Microtubule-based process & 21996 & 0.32 \\
\hline Q3ZCM7 & Tubulin beta-8 chain ${ }^{D}$ & Structural constituent of cytoskeleton & 8805 & 0.32 \\
\hline Q9BVA1 & Tubulin beta-2B chain ${ }^{D}$ & Microtubule-based process & 26225 & 0.28 \\
\hline P07437 & Tubulin beta chain ${ }^{\mathrm{D}}$ & Microtubule-based process & 26437 & 0.28 \\
\hline Q13885 & Tubulin beta-2A chain ${ }^{D}$ & Microtubule-based process & 26225 & 0.28 \\
\hline Q13509 & Tubulin beta-3 chain ${ }^{D}$ & Microtubule-based process & 19550 & 0.24 \\
\hline A0A0B4J269 & Uncharacterized protein ${ }^{D}$ & Microtubule-based process & 8751 & 0.24 \\
\hline P08729 & Keratin_type II cytoskeletal 7 D & Structural constituent of cytoskeleton & 478 & 0.23 \\
\hline Q9NY65 & Tubulin alpha-8 chain ${ }^{D}$ & Microtubule-based process & 11965 & 0.23 \\
\hline Q71U36 & Tubulin alpha- $1 \mathrm{~A}$ chain ${ }^{\mathrm{D}}$ & Microtubule-based process & 38018 & 0.22 \\
\hline
\end{tabular}




\begin{tabular}{|c|c|c|c|c|}
\hline Accession & Description & Biologic process & Score & Ratio I:NO \\
\hline G3V3R4 & HCG1983504_isoform CRA_c ${ }^{D}$ & Microtubule-based process & 16551 & 0.21 \\
\hline Q13748 & Tubulin alpha-3C/D chain ${ }^{D}$ & Microtubule-based process & 12692 & 0.21 \\
\hline Q6PEY2 & Tubulin alpha-3E chain ${ }^{D}$ & Microtubule-based process & 8817 & 0.21 \\
\hline P68363 & Tubulin alpha-1B chain ${ }^{D}$ & Microtubule-based process & 37783 & 0.21 \\
\hline G3V2N6 & HCG1983504_isoform CRA_d ${ }^{D}$ & Microtubule-based process & 16551 & 0.21 \\
\hline P68366 & Tubulin alpha-4A chain ${ }^{\mathrm{D}}$ & Microtubule-based process & 12442 & 0.20 \\
\hline Q9BQE3 & Tubulin alpha-1C chain ${ }^{D}$ & Microtubule-based process & 34846 & 0.20 \\
\hline F5H5D3 & Tubulin alpha chain ${ }^{\mathrm{D}}$ & Microtubule-based process & 34846 & 0.20 \\
\hline Q9UMX9 & Membrane-associated transporter protein ${ }^{\mathrm{F}}$ & Sensory transduction & 800 & 0.08 \\
\hline P02768 & Serum albumin ${ }^{\mathrm{C}}$ & Transport & 72906 & 25.53 \\
\hline C9JKR2 & Albumin_isoform CRA_k ${ }^{\mathrm{C}}$ & Transport & 28569 & 18.17 \\
\hline P01857 & Immunoglobulin heavy constant gamma $1^{\mathrm{B}}$ & Adaptive immunity & 12257 & 3.00 \\
\hline P01023 & Alpha-2-macroglobulin ${ }^{\mathrm{G}}$ & Regulation of complement activation & 1004 & 2.23 \\
\hline P68032 & Actin_alpha cardiac muscle $1^{\mathrm{D}}$ & Structural constituent of cytoskeleton & 1208 & 0.49 \\
\hline P68133 & Actin_alpha skeletal muscle ${ }^{\mathrm{D}}$ & Structural constituent of cytoskeleton & 1190 & 0.49 \\
\hline P63267 & Actin_ gamma-enteric smooth muscle ${ }^{\mathrm{D}}$ & Structural constituent of cytoskeleton & 1208 & 0.49 \\
\hline P62736 & Actin_aortic smooth muscle ${ }^{D}$ & Structural constituent of cytoskeleton & 1208 & 0.48 \\
\hline Q6S8J3 & POTE ankyrin domain family member EL & Unknown & 1142 & 0.44 \\
\hline A5A3E0 & POTE ankyrin domain family member $\mathrm{FL}$ & Unknown & 1132 & 0.44 \\
\hline P0CG38 & POTE ankyrin domain family member ${ }^{\mathrm{IL}}$ & Unknown & 1085 & 0.41 \\
\hline P0CG39 & POTE ankyrin domain family member ${ }^{\mathrm{J} L}$ & Unknown & 568 & 0.35 \\
\hline P02042 & Hemoglobin subunit delta ${ }^{\mathrm{C}}$ & Oxygen transport & 3864 & 0.11 \\
\hline Q15059 & Bromodomain-containing protein $3^{\mathrm{F}}$ & Transcription regulation & 2487 & 0.10 \\
\hline G3V1N2 & HCG1745306_isoform CRA_a ${ }^{\mathrm{C}}$ & Oxygen transport & 3312 & 0.01 \\
\hline P69905 & Hemoglobin subunit alpha ${ }^{\mathrm{C}}$ & Oxygen transport & 8134 & 0.01 \\
\hline P68871 & Hemoglobin subunit beta ${ }^{\mathrm{C}}$ & Oxygen transport & 8969 & 0.00 \\
\hline
\end{tabular}

Proteins were classified according to Uniprot database: A - Metabolism and energy pathways; B - Immune response; C - Transport; D - Structure; E - DNA/RNA regulation and repair; F - Cell communication and signal transduction; G - Cell growth and/or maintenance; H- Differentiation of neural cells; I- Apoptosis; J- Stress response; K- Ions regulation and binding; L- Unknown. *From accession number P02768 starts Ratio NE:I.

Table 3. Human proteins identified exclusively in normal, inflamed or necrotic pulp

\begin{tabular}{|c|c|c|c|}
\hline \multicolumn{4}{|c|}{ Normal pulp } \\
\hline Accession & Description & Biologic process & Score \\
\hline E2QRG7 & 4-hydroxybenzoate polyprenyltransferase_ mitochondrial A & Ubiquinone biosynthesis & 424.48 \\
\hline Q8IUX7 & Adipocyte enhancer-binding protein $1^{\mathrm{F}}$ & Transcription regulation & 281.92 \\
\hline F2Z324 & Aldehyde dehydrogenase 1 family member $\mathrm{L} 1$ isoform $2 \mathrm{~L}$ & Unknown & 354.48 \\
\hline P02765 & Alpha-2-HS-glycoprotein ${ }^{\text {B }}$ & Acute-phase response & 334 \\
\hline HOYMF8 & Ammonium transporter Rh type C ${ }^{D}$ & Component of membrane & 751.41 \\
\hline P00966 & Argininosuccinate synthase ${ }^{A}$ & Arginine biosynthesis & 178.45 \\
\hline HoYH81 & ATP synthase subunit beta (Fragment) ${ }^{A}$ & ATP synthesis & 289.75 \\
\hline
\end{tabular}




\begin{tabular}{|c|c|c|c|}
\hline Accession & Description & Biologic process & Score \\
\hline P06576 & ATP synthase subunit beta_mitochondrial ${ }^{\mathrm{C}}$ & Transport & 548.43 \\
\hline Q9NUQ8 & ATP-binding cassette sub-family F member $3^{\text {B }}$ & Antiviral defense & 217.99 \\
\hline P08237 & ATP-dependent 6-phosphofructokinase_muscle type ${ }^{\text {A }}$ & Glycolysis & 439.21 \\
\hline P49407 & Beta-arrestin-1 $\mathrm{F}$ & Transcription regulation & 243.29 \\
\hline P21810 & Biglycan D & $\begin{array}{l}\text { Extracellular matrix } \\
\text { structural constituent }\end{array}$ & 277.04 \\
\hline P22223 & Cadherin-3 $\mathrm{F}$ & Sensory transduction & 414.89 \\
\hline Q9H9S4 & Calcium-binding protein 39-like ${ }^{\mathrm{G}}$ & Cell cycle arrest & 785.13 \\
\hline P29762 & Cellular retinoic acid-binding protein $1^{\mathrm{C}}$ & Transport & 1319.56 \\
\hline X6RIU2 & Cilia- and flagella-associated protein 221 (Fragment) ${ }^{\mathrm{D}}$ & Component of cytoskeleton & 158.14 \\
\hline Q96N23 & Cilia- and flagella-associated protein $54^{\mathrm{D}}$ & Component of cytoskeleton & 864.57 \\
\hline P26441 & Ciliary neurotrophic factor ${ }^{\mathrm{H}}$ & $\begin{array}{l}\text { Differentiation. Neurogenesis. } \\
\text { Growth factor }\end{array}$ & 150.4 \\
\hline A0A0A0MT56 & Cleavage stimulation factor subunit 2 (Fragment) $\mathrm{E}$ & mRNA-processing & 428.34 \\
\hline Q9GZT6 & Coiled-coil domain-containing protein 90B_mitochondrial ${ }^{\mathrm{D}}$ & Mitochondrial membrane & 271 \\
\hline J3QT66 & COP9 signalosome complex subunit $7 \mathrm{~b}^{\mathrm{B}}$ & Host-virus interaction & 847.96 \\
\hline Q2NKJ3 & CST complex subunit CTC $1^{\mathrm{G}}$ & Regulation of fibroblast proliferation & 586.38 \\
\hline K7EJ26 & CUGBP Elav-like family member 4 (Fragment) ${ }^{\mathrm{E}}$ & mRNA-processing & 247.83 \\
\hline 075891 & Cytosolic 10-formyltetrahydrofolate dehydrogenase ${ }^{\mathrm{J}}$ & Oxidoreductase & 362.58 \\
\hline Q07507 & Dermatopontin ${ }^{D}$ & $\begin{array}{l}\text { Extracellular matrix } \\
\text { structural constituent }\end{array}$ & 1412.86 \\
\hline 075907 & Diacylglycerol 0-acyltransferase $1^{\text {A }}$ & Acyltransferase. Transferase & 290.99 \\
\hline Q16555 & Dihydropyrimidinase-related protein $2^{\mathrm{H}}$ & Differentiation. Neurogenesis & 169.43 \\
\hline P53602 & Diphosphomevalonate decarboxylase ${ }^{\mathrm{G}}$ & Regulation of cell proliferation & 552.3 \\
\hline $\mathrm{H} 7 \mathrm{COV} 2$ & DNA repair protein RAD50 (Fragment) ${ }^{B}$ & Host-virus interaction & 234.66 \\
\hline P38935 & DNA-binding protein SMUBP-2 $\mathrm{F}$ & Transcription regulation & 197.26 \\
\hline A0PK19 & EPGN protein ${ }^{G}$ & Regulation of cell proliferation & 1566.9 \\
\hline Q6UW88 & Epigen $^{\mathrm{G}}$ & Regulation of cell proliferation & 1566.9 \\
\hline P60842 & Eukaryotic initiation factor $4 \mathrm{~A}-\mathrm{I}^{\mathrm{B}}$ & Host-virus interaction & 175.34 \\
\hline Q04637 & Eukaryotic translation initiation factor 4 gamma $1^{\mathrm{B}}$ & Host-virus interaction & 280.67 \\
\hline Q9NPD3 & Exosome complex component RRP41 E & rRNA processing & 340.1 \\
\hline Q9UK22 & F-box only protein $2^{\mathrm{A}}$ & Regulation of protein ubiquitination & 280.14 \\
\hline Q969U6 & F-box/WD repeat-containing protein $5^{\mathrm{A}}$ & Regulation of protein ubiquitination & 335.47 \\
\hline A0A0A0MS75 & FGF receptor activating protein 1 isoform CRA_e ${ }^{D}$ & Integral component of membrane & 229.6 \\
\hline Q06828 & Fibromodulin ${ }^{\mathrm{D}}$ & $\begin{array}{l}\text { Extracellular matrix } \\
\text { structural constituent }\end{array}$ & 484.9 \\
\hline G5E9X3 & Fibronectin type III domain containing 3A_ isoform CRA_f F & Cell-cell adhesion & 263.94 \\
\hline Q9Y2H6 & Fibronectin type-III domain-containing protein $3 \mathrm{~A}^{\mathrm{F}}$ & Cell-cell adhesion & 283.11 \\
\hline H3BQN4 & Fructose-bisphosphate aldolase ${ }^{\mathrm{A}}$ & Glycolytic process & 577.74 \\
\hline P04075 & Fructose-bisphosphate aldolase A A & Glycolytic process & 591.64 \\
\hline P09382 & Galectin-1 I & Apoptosis & 4761.72 \\
\hline Q9UBS5 & Gamma-aminobutyric acid type B receptor subunit $1^{\mathrm{A}}$ & G-protein coupled receptor & 433.53 \\
\hline
\end{tabular}




\begin{tabular}{|c|c|c|c|}
\hline Accession & Description & Biologic process & Score \\
\hline Q99501 & GAS2-like protein 1 D & Component of cytoskeleton & 299.88 \\
\hline H7C4Q8 & $\begin{array}{l}\text { General transcription factor II-I repeat domain- } \\
\text { containing protein } 1 \text { (Fragment) } \mathrm{F}\end{array}$ & Transcription regulation & 168.04 \\
\hline Q14687 & Genetic suppressor element $1 \mathrm{~L}$ & Unknown & 118.64 \\
\hline Q86VD9 & GPI mannosyltransferase $4{ }^{\mathrm{A}}$ & GPI-anchor biosynthesis & 218.44 \\
\hline G3V3J6 & HCG1983504_isoform CRA_b ${ }^{D}$ & Microtubule-based process & 10798.74 \\
\hline Q9H583 & HEAT repeat-containing protein $1 \mathrm{~F}$ & Transcription regulation & 391.17 \\
\hline Q86XA9 & HEAT repeat-containing protein $5 \mathrm{~A}^{\mathrm{F}}$ & Transcription regulation & 238.55 \\
\hline P04792 & Heat shock protein beta- $1 \mathrm{~J}$ & Stress response & 1700.43 \\
\hline Q9Y5N1 & Histamine $\mathrm{H} 3$ receptor ${ }^{\mathrm{A}}$ & G-protein coupled receptor & 188.39 \\
\hline Q96A08 & Histone $\mathrm{H} 2 \mathrm{~B}$ type $1-\mathrm{A}^{\mathrm{B}}$ & Inflammatory response & 1914.55 \\
\hline Q14571 & Inositol 1_4_5-trisphosphate receptor type $2^{\mathrm{C}}$ & Transport & 271.01 \\
\hline P19823 & Inter-alpha-trypsin inhibitor heavy chain $\mathrm{H} 2{ }^{\mathrm{A}}$ & Cellular protein metabolic process & 371.22 \\
\hline V9GXZ7 & Kin of IRRE-like protein 2 (Fragment) ${ }^{\mathrm{L}}$ & Unknown & 462.22 \\
\hline Q96Q89 & Kinesin-like protein KIF20B ${ }^{\mathrm{G}}$ & Cell division. mitosis & 844.1 \\
\hline HOYEHO & $\begin{array}{l}\text { Large neutral amino acids transporter } \\
\text { small subunit } 3 \text { (Fragment) }{ }^{D}\end{array}$ & Integral component of membrane & 736.6 \\
\hline 075845 & Lathosterol oxidase $^{\mathrm{A}}$ & Lipid metabolism & 169.98 \\
\hline Q8N653 & Leucine-zipper-like transcriptional regulator $1^{\mathrm{F}}$ & Transcription factor & 161.39 \\
\hline Q8NHJ6 & $\begin{array}{l}\text { Leukocyte immunoglobulin-like receptor } \\
\text { subfamily B member } 4^{\text {B }}\end{array}$ & Adaptive immunity & 315.03 \\
\hline P51884 & Lumican ${ }^{\mathrm{D}}$ & $\begin{array}{l}\text { Extracellular matrix } \\
\text { structural constituent }\end{array}$ & 5091.27 \\
\hline Q6UWQ5 & Lysozyme-like protein $1{ }^{\text {в }}$ & Defense response to bacteria & 847.95 \\
\hline Q7Z4W2 & Lysozyme-like protein $2^{\text {B }}$ & Defense response to bacteria & 847.95 \\
\hline Q14168 & MAGUK p55 subfamily member $2^{\mathrm{F}}$ & Excitatory postsynaptic potential & 700.69 \\
\hline Q9H3U5 & Major facilitator superfamily domain-containing protein $1^{\mathrm{C}}$ & Transport & 167.24 \\
\hline C9JQX2 & Mannosyltransferase ${ }^{\mathrm{A}}$ & Glycosyltransferase & 210.23 \\
\hline E5RJR3 & Methionine adenosyltransferase 2 subunit beta ${ }^{A}$ & One-carbon metabolism & 683.62 \\
\hline P25189 & Myelin protein P0 ${ }^{\mathrm{I}}$ & Regulation of apoptotic process & 366.82 \\
\hline P60660 & Myosin light polypeptide $6^{\mathrm{K}}$ & Calcium ion binding & 430.43 \\
\hline Q9UK23 & $\begin{array}{l}\mathrm{N} \text {-acetylglucosamine-1-phosphodiester } \\
\text { alpha-N-acetylglucosaminidase }{ }^{\mathrm{A}}\end{array}$ & Protein glycosylation & 246.65 \\
\hline A0A087WYD0 & $\begin{array}{l}\text { NADH dehydrogenase (Ubiquinone) } 1 \text { beta } \\
\text { subcomplex_5_ } 16 \mathrm{kDa}_{-} \text {isoform CRA_g }{ }^{\mathrm{C}}\end{array}$ & Transport & 379.52 \\
\hline 043674 & $\begin{array}{l}\text { NADH dehydrogenase [ubiquinone] } 1 \text { beta } \\
\text { subcomplex subunit 5_ mitochondrial }{ }^{\mathrm{C}}\end{array}$ & Transport & 379.52 \\
\hline 000308 & NEDD4-like E3 ubiquitin-protein ligase WWP2 ${ }^{\text {в }}$ & Host-virus interaction & 261.84 \\
\hline 000533 & Neural cell adhesion molecule L1-like protein ${ }^{\mathrm{H}}$ & Differentiation. Neurogenesis & 238.35 \\
\hline P12036 & Neurofilament heavy polypeptide ${ }^{\mathrm{D}}$ & $\begin{array}{l}\text { Structural constituent } \\
\text { of cytoskeleton }\end{array}$ & 471.82 \\
\hline P07196 & Neurofilament light polypeptide ${ }^{\mathrm{D}}$ & $\begin{array}{l}\text { Structural constituent } \\
\text { of cytoskeleton }\end{array}$ & 645.68 \\
\hline Q9NZ94 & Neuroligin-3 $\mathrm{F}$ & Cell adhesion & 470.51 \\
\hline
\end{tabular}




\begin{tabular}{|c|c|c|c|}
\hline Accession & Description & Biologic process & Score \\
\hline Q7RTR2 & NLR family CARD domain-containing protein $3^{\text {B }}$ & Regulation of inflammatory response & 180.39 \\
\hline H3BLT9 & NOD3 protein_isoform CRA_d ${ }^{D}$ & Microtubule organizing center & 180.39 \\
\hline Q14980 & Nuclear mitotic apparatus protein 1 F & Cell division & 281.88 \\
\hline Q14686 & Nuclear receptor coactivator $6^{\mathrm{F}}$ & Transcription regulation & 253.67 \\
\hline A0A126GWK9 & Olfactory receptor ${ }^{\mathrm{F}}$ & Sensory transduction & 305.24 \\
\hline 043869 & Olfactory receptor $2 \mathrm{~T} 1{ }^{\mathrm{F}}$ & Sensory transduction & 305.24 \\
\hline Q6IFN5 & Olfactory receptor 7E24 F & Sensory transduction & 220.6 \\
\hline HoY2Y4 & Palmitoyltransferase (Fragment) A & Kinase activity & 212.83 \\
\hline 095497 & Pantetheinase $^{\mathrm{J}}$ & Response to oxidative stress & 239.94 \\
\hline P26022 & Pentraxin-related protein РТХ 3 в & Inflammatory response & 159.12 \\
\hline Q9Y536 & Peptidyl-prolyl cis-trans isomerase A-like $4 \mathrm{~A}^{\mathrm{A}}$ & Catalytic activity & 511.68 \\
\hline Q8NEB9 & Phosphatidylinositol 3-kinase catalytic subunit type $3^{\text {I }}$ & Autophagy & 518.24 \\
\hline Q9UHJ9 & Post-GPI attachment to proteins factor $2 \mathrm{~A}$ & GPI-anchor biosynthesis & 229.6 \\
\hline Q01860 & POU domain_class 5_transcription factor 1 F & Transcription regulation & 190.11 \\
\hline P02545 & Prelamin-A/C ${ }^{\mathrm{A}}$ & $\begin{array}{l}\text { Regulation of apoptotic } \\
\text { signaling pathway }\end{array}$ & 405.48 \\
\hline Q9UMS4 & Pre-mRNA-processing factor $19 \mathrm{E}$ & mRNA processing & 353.75 \\
\hline Q96I59 & Probable asparagine--tRNA ligase_ mitochondrial A & Protein biosynthesis & 191.32 \\
\hline Q15034 & Probable E3 ubiquitin-protein ligase HERC3 A & Ubl conjugation pathway & 82.2 \\
\hline Q16651 & Prostasin ${ }^{K}$ & Regulation of sodium ion transport & 275.33 \\
\hline HOYHR3 & Protein phosphatase Slingshot homolog 1 (Fragment) ${ }^{\mathrm{G}}$ & Actin cytoskeleton organization & 255.57 \\
\hline Q99497 & Protein/nucleic acid deglycase DJ-1 J & Stress response & 784.37 \\
\hline H3BRZO & $\begin{array}{l}\text { Putative sodium-coupled neutral amino } \\
\text { acid transporter } 7 \text { (Fragment) }{ }^{\mathrm{D}}\end{array}$ & Integral component of membrane & 672.03 \\
\hline B4DNK4 & Pyruvate kinase ${ }^{\mathrm{A}}$ & Kinase activity & 458.75 \\
\hline P14618 & Pyruvate kinase PKM A & Kinase activity & 458.75 \\
\hline P26374 & Rab proteins geranylgeranyltransferase component A 2 C & Intracellular protein transport & 618.53 \\
\hline P21860 & Receptor tyrosine-protein kinase erbB-3 D & Receptor of cell membrane & 271.71 \\
\hline Q12913 & Receptor-type tyrosine-protein phosphatase eta ${ }^{\mathrm{D}}$ & Receptor of cell membrane & 436.47 \\
\hline E9PGT3 & Ribosomal protein S6 kinase ${ }^{\mathrm{F}}$ & Intracellular signal transduction & 415.96 \\
\hline Q15418 & Ribosomal protein S6 kinase alpha-1 ${ }^{\mathrm{F}}$ & Intracellular signal transduction & 430.79 \\
\hline Q6P3W7 & SCY1-like protein $2^{\mathrm{C}}$ & Endosome to lisossome transport & 144.69 \\
\hline P59797 & Selenoprotein V L & Unknown & 3591.64 \\
\hline Q9H3S1 & Semaphorin- $4 \mathrm{~A}^{\mathrm{H}}$ & Differentiation. Neurogenesis & 898.66 \\
\hline 095754 & Semaphorin $-4 \mathrm{~F}^{\mathrm{H}}$ & Differentiation. Neurogenesis & 257.33 \\
\hline Q05519 & Serine/arginine-rich splicing factor $11^{\mathrm{E}}$ & mRNA processing & 1467.45 \\
\hline Q8WU08 & Serine/threonine-protein kinase $32 \mathrm{~A}^{\mathrm{F}}$ & Intracellular signal transduction & 292.95 \\
\hline Q9H2K8 & Serine/threonine-protein kinase $\mathrm{TA03}{ }^{\mathrm{E}}$ & DNA repair & 607.16 \\
\hline 043147 & Small G protein signaling modulator $2^{\mathrm{C}}$ & Intracellular protein transport & 738.5 \\
\hline Q8N4F4 & Solute carrier family 22 member $24^{\mathrm{K}}$ & Ion transport & 317.43 \\
\hline
\end{tabular}




\begin{tabular}{|c|c|c|c|}
\hline Accession & Description & Biologic process & Score \\
\hline P00441 & Superoxide dismutase $[\mathrm{Cu}-\mathrm{Zn}]^{\mathrm{J}}$ & Antioxidant. Oxidoreductase & 1233.87 \\
\hline Q9UMS6 & Synaptopodin-2 $\mathrm{F}$ & Regulation of cell migration & 289.93 \\
\hline Q9Y6H5 & Synphilin-1 A & Cellular protein metabolic process & 224.06 \\
\hline Q9NYW2 & Taste receptor type 2 member 8 A & G-protein coupled receptor & 173.03 \\
\hline Q8IWY7 & Tau-tubulin kinase ${ }^{\mathrm{A}}$ & Kinase activity & 231.03 \\
\hline P24821 & Tenascin ${ }^{\mathrm{F}}$ & Cell adhesion & 788.89 \\
\hline Q5R3I4 & Tetratricopeptide repeat protein $38^{\mathrm{L}}$ & Unknown & 164.5 \\
\hline Q96FV9 & THO complex subunit $1^{\mathrm{F}}$ & Transcription regulation & 165.16 \\
\hline Q14135 & Transcription cofactor vestigial-like protein $4 \mathrm{~F}$ & Transcription regulation & 320.85 \\
\hline Q15582 & Transforming growth factor-beta-induced protein ig-h3 ${ }^{\mathrm{F}}$ & Cell adhesion & 699.53 \\
\hline Q7Z6W1 & Transmembrane and coiled-coil domain-containing protein $2^{\mathrm{D}}$ & Integral component of membrane & 383.03 \\
\hline Q9H4B7 & Tubulin beta-1 chain ${ }^{D}$ & $\begin{array}{l}\text { Structural constituent } \\
\text { of cytoskeleton }\end{array}$ & 1944.92 \\
\hline Q9UJT1 & Tubulin delta chain ${ }^{\mathrm{D}}$ & $\begin{array}{l}\text { Structural constituent } \\
\text { of cytoskeleton }\end{array}$ & 493.65 \\
\hline A8MXF1 & Tyrosine-protein phosphatase non-receptor type $5^{\mathrm{A}}$ & Protein phosphatase & 355.82 \\
\hline A0A0B4J269 & Uncharacterized protein ${ }^{D}$ & Microtubule-based process & 8750.79 \\
\hline Q8NBR9 & Uncharacterized protein C11 orf72 ${ }^{\mathrm{L}}$ & Unknown & 310.42 \\
\hline V9GY35 & Uncharacterized protein C1orf109 (Fragment) ${ }^{\mathrm{L}}$ & Unknown & 240.6 \\
\hline Q6ZUG5 & Uncharacterized protein FLJ43738 ${ }^{\mathrm{L}}$ & Unknown & 992.96 \\
\hline D6RBZ9 & Uncharacterized protein FLJ43738 (Fragment) ${ }^{\mathrm{L}}$ & Unknown & 990.13 \\
\hline Q92628 & Uncharacterized protein KIAA0232 ${ }^{\mathrm{L}}$ & Unknown & 583.39 \\
\hline D6REK0 & Uncharacterized protein KIAA0232 ${ }^{\mathrm{L}}$ & Unknown & 568.86 \\
\hline P 10746 & Uroporphyrinogen-III synthase ${ }^{\mathrm{A}}$ & Heme biosynthesis & 212.17 \\
\hline P04004 & Vitronectin ${ }^{\mathrm{F}}$ & Cell adhesion & 728.59 \\
\hline Q06432 & Voltage-dependent calcium channel gamma-1 subunit ${ }^{K}$ & Calcium transport & 219.37 \\
\hline Q5MNZ6 & WD repeat domain phosphoinositide-interacting protein $3^{\mathrm{I}}$ & Autophagy of nucleus & 228.89 \\
\hline Q13105 & Zinc finger and BTB domain-containing protein $17^{\mathrm{F}}$ & Transcription regulation & 302.68 \\
\hline Q6PJT7 & Zinc finger $\mathrm{CCCH}$ domain-containing protein $14^{\mathrm{E}}$ & Regulation of mRNA stability & 331.85 \\
\hline Q09FC8 & Zinc finger protein $415^{\mathrm{F}}$ & Transcription regulation & 192.42 \\
\hline Q96MU6 & Zinc finger protein $778^{\mathrm{F}}$ & Transcription regulation & 562.65 \\
\hline \multicolumn{4}{|c|}{ Inflamed pulp } \\
\hline Accession & Description & Biologic process & Score \\
\hline P62280 & $40 \mathrm{~S}$ ribosomal protein $\mathrm{S} 11^{\mathrm{F}}$ & Translational initiation & 351.39 \\
\hline Q13085 & Acetyl-CoA carboxylase $1^{\mathrm{A}}$ & Lipid metabolism & 394.31 \\
\hline P78348 & Acid-sensing ion channel $1^{\mathrm{K}}$ & Ion transport & 1387.23 \\
\hline A0A1X7SBU6 & Adhesion G protein-coupled receptor V1 (Fragment) ${ }^{\mathrm{D}}$ & Integral component of membrane & 208.16 \\
\hline Q9NVD7 & Alpha-parvin ${ }^{\mathrm{G}}$ & Angiogenesis & 174.54 \\
\hline Q86UQ4 & ATP-binding cassette sub-family A member 13 (Fragment) ${ }^{\mathrm{C}}$ & Transport & 281.18 \\
\hline 094911 & ATP-binding cassette sub-family A member 8 (Fragment) ${ }^{c}$ & Transmembrane transport & 190.11 \\
\hline Q8WXE1 & ATR-interacting protein ${ }^{\mathrm{E}}$ & Response to DNA damage & 636.8 \\
\hline
\end{tabular}




\begin{tabular}{|c|c|c|c|}
\hline Accession & Description & Biologic process & Score \\
\hline P17213 & Bactericidal permeability-increasing protein ${ }^{B}$ & Antibacterial humoral response & 284.17 \\
\hline P02730 & Band 3 anion transport protein ${ }^{k}$ & Ion transport & 243.95 \\
\hline Q96T60 & Bifunctional polynucleotide phosphatase/ kinase $^{\mathrm{E}}$ & Response to DNA damage & 229.66 \\
\hline P00915 & Carbonic anhydrase $1^{\mathrm{K}}$ & Bicarbonate transport & 364.93 \\
\hline P00918 & Carbonic anhydrase $2^{\mathrm{K}}$ & Bicarbonate transport & 641.72 \\
\hline Q9NS85 & Carbonic anhydrase-related protein $10^{\mathrm{K}}$ & Zinc ion binding & 179.75 \\
\hline P51948 & CDK-activating kinase assembly factor MAT $1{ }^{F}$ & Transcription regulation & 228.15 \\
\hline P00451 & Coagulation factor VIII ${ }^{\mathrm{B}}$ & Acute-phase response & 548.5 \\
\hline H0YK65 & Coiled-coil domain-containing 9B (Fragment) ${ }^{\mathrm{L}}$ & Unknown & 372.31 \\
\hline Q9Y2V7 & Conserved oligomeric Golgi complex subunit $6^{\mathrm{C}}$ & Protein transport & 382.37 \\
\hline Q8TEY5 & $\begin{array}{l}\text { Cyclic AMP-responsive element-binding } \\
\text { protein 3-like protein } 4 \mathrm{~F}\end{array}$ & Transcription regulation & 314.59 \\
\hline P55273 & Cyclin-dependent kinase 4 inhibitor $\mathrm{D}^{\mathrm{I}}$ & Autophagic cell death & 360.12 \\
\hline Q68DD2 & Cytosolic phospholipase A2 zeta ${ }^{A}$ & Lipid metabolism & 279.68 \\
\hline P30038 & $\begin{array}{l}\text { Delta-1-pyrroline-5-carboxylate } \\
\text { dehydrogenase_ mitochondrial }{ }^{\mathrm{J}}\end{array}$ & Oxidoreductase. proline metabolism & 191.36 \\
\hline P78352 & Disks large homolog $4^{\mathrm{F}}$ & Cell adhesion & 233.8 \\
\hline P36507 & Dual specificity mitogen-activated protein kinase $2^{\mathrm{A}}$ & Activation of protein kinase activity & 240.42 \\
\hline HoYD30 & Dynein assembly factor 3_ axonemal (Fragment) ${ }^{\mathrm{F}}$ & Axonemal dynein complex assembly & 309.68 \\
\hline Q14118 & Dystroglycan $^{\mathrm{G}}$ & Angiogenesis & 383.01 \\
\hline Q8N2H9 & E3 ubiquitin-protein ligase pellino homolog 3 A & Ubl conjugation pathway & 1102.45 \\
\hline K7EII6 & Echinoderm microtubule-associated protein-like 2 (Fragment) $\mathrm{F}$ & $\begin{array}{c}\text { Regulation of microtubule } \\
\text { nucleation }\end{array}$ & 230.16 \\
\hline Q05BV3 & Echinoderm microtubule-associated protein-like $5^{\mathrm{D}}$ & Microtubule binding & 308.9 \\
\hline P43897 & Elongation factor $\mathrm{Ts}_{-}$mitochondrial ${ }^{\mathrm{G}}$ & Protein biosynthesis & 215.14 \\
\hline Q5T6L9 & $\begin{array}{l}\text { Endoplasmic reticulum membrane- } \\
\text { associated RNA degradation protein }{ }^{G}\end{array}$ & Developmental protein & 440.87 \\
\hline 015360 & Fanconi anemia group A protein ${ }^{\mathrm{E}}$ & Response to DNA damage & 156.29 \\
\hline Q14CZ7 & FAST kinase domain-containing protein 3_ mitochondrial ${ }^{\mathrm{A}}$ & Protein kinase activity & 216.49 \\
\hline 094887 & FERM_ARHGEF and pleckstrin domain-containing protein $2^{\mathrm{G}}$ & Osteoclast differentiation & 394.64 \\
\hline P02679 & Fibrinogen gamma chain ${ }^{\mathrm{F}}$ & Hemostasis & 117.71 \\
\hline Q4L180 & Filamin A-interacting protein 1-like ${ }^{\mathrm{I}}$ & Regulation of apoptosis process & 259.28 \\
\hline Q9NSN8 & Gamma-1-syntrophin $\mathrm{F}$ & Cell communication & 273.12 \\
\hline P36383 & Gap junction gamma- 1 protein ${ }^{\mathrm{G}}$ & Cell development. Vasculogenesis & 179.45 \\
\hline Q5T442 & Gap junction gamma-2 protein ${ }^{G}$ & Cell development. Vasculogenesis & 307.56 \\
\hline Q13630 & GDP-L-fucose synthase ${ }^{\mathrm{J}}$ & Oxidoreductase & 120.68 \\
\hline Q6UWF4 & GLGQ5807 D & Membrane component & 325.59 \\
\hline Q92805 & Golgin subfamily A member $1^{\mathrm{D}}$ & Structural component & 197.06 \\
\hline A0A1W2PNZ5 & GPI transamidase component PIG-T I & Neuron apoptotic process & 369.7 \\
\hline P62826 & GTP-binding nuclear protein $\operatorname{Ran}^{\mathrm{G}}$ & Cell division & 306.27 \\
\hline A0A0A6YYF2 & HCG1811249_isoform CRA_e ${ }^{F}$ & Regulation of cell adhesion & 277.46 \\
\hline A0A0A0MTS5 & HCG1811249_isoform CRA_f ${ }^{F}$ & Regulation of cell adhesion & 274.02 \\
\hline
\end{tabular}




\begin{tabular}{|c|c|c|c|}
\hline Accession & Description & Biologic process & Score \\
\hline A0A0U1RR32 & Histone $\mathrm{H} 2 \mathrm{~A}^{\mathrm{E}}$ & DNA-binding & 176.75 \\
\hline PoCoS8 & Histone $\mathrm{H} 2 \mathrm{~A}$ type $1^{\mathrm{E}}$ & DNA-binding & 176.75 \\
\hline Q96QV6 & Histone $\mathrm{H} 2 \mathrm{~A}$ type $1-\mathrm{A}^{\mathrm{E}}$ & DNA-binding & 176.75 \\
\hline P04908 & Histone $\mathrm{H} 2 \mathrm{~A}$ type $1-\mathrm{B} / \mathrm{E}^{\mathrm{E}}$ & DNA-binding & 176.75 \\
\hline Q93077 & Histone $\mathrm{H} 2 \mathrm{~A}$ type $1-\mathrm{C}^{\mathrm{E}}$ & DNA-binding & 176.75 \\
\hline P20671 & Histone $\mathrm{H} 2 \mathrm{~A}$ type $1-\mathrm{D}^{\mathrm{E}}$ & DNA-binding & 176.75 \\
\hline Q96KK5 & Histone $\mathrm{H} 2 \mathrm{~A}$ type $1-\mathrm{H}^{\mathrm{E}}$ & DNA-binding & 176.75 \\
\hline Q99878 & Histone $\mathrm{H} 2 \mathrm{~A}$ type $1-\mathrm{J} \mathrm{E}$ & DNA-binding & 176.75 \\
\hline Q6FI13 & Histone $\mathrm{H} 2 \mathrm{~A}$ type $2-\mathrm{A}^{\mathrm{E}}$ & DNA-binding & 176.75 \\
\hline Q8IUE6 & Histone $\mathrm{H} 2 \mathrm{~A}$ type $2-\mathrm{B}$ E & DNA-binding & 176.75 \\
\hline Q16777 & Histone $\mathrm{H} 2 \mathrm{~A}$ type $2-\mathrm{C}^{\mathrm{E}}$ & DNA-binding & 176.75 \\
\hline Q7L7LO & Histone H2A type 3 E & DNA-binding & 176.75 \\
\hline Q9BTM1 & Histone H2A.J E & DNA-binding & 176.75 \\
\hline Q71UI9 & Histone H2A.V E & DNA-binding & 176.75 \\
\hline PoCoS5 & Histone H2A.Z ${ }^{\mathrm{E}}$ & DNA-binding & 176.75 \\
\hline P16104 & Histone $\mathrm{H} 2 \mathrm{AX}^{\mathrm{E}}$ & DNA-binding & 176.75 \\
\hline P62805 & Histone $\mathrm{H} 4^{\mathrm{E}}$ & DNA-binding & 1795.98 \\
\hline I3L3R1 & Homeobox B8_isoform CRA_a ${ }^{F}$ & Transcription regulation & 236.2 \\
\hline P17481 & Homeobox protein Hox-B8 $\mathrm{F}$ & Transcription regulation & 236.2 \\
\hline P31273 & Homeobox protein $\mathrm{Hox}-\mathrm{C} 8 \mathrm{~F}$ & Transcription regulation & 236.2 \\
\hline J3QL30 & Hydrocephalus-inducing protein homolog (Fragment) ${ }^{\mathrm{L}}$ & Unknown & 536.84 \\
\hline Q7Z5J1 & Hydroxysteroid 11-beta-dehydrogenase 1 -like protein ${ }^{\mathrm{J}}$ & Oxidoreductase & 388.82 \\
\hline А0A0B4J2B6 & $\begin{array}{l}\text { Immunoglobulin heavy variable } 2 / 0 R 16- \\
5 \text { (non-functional) (Fragment) }{ }^{\mathrm{B}}\end{array}$ & Innate immune response & 410.2 \\
\hline HOYBQ1 & Integrator complex subunit 8 (Fragment) ${ }^{\mathrm{E}}$ & snRNA processing & 244.63 \\
\hline Q8IU57 & Interferon lambda receptor $1^{\mathrm{B}}$ & Antiviral defense & 262.8 \\
\hline A0A1B0GTI5 & Interleukin-10 receptor subunit beta (Fragment) B & Inflammatory response & 326.35 \\
\hline Q15811 & Intersectin-1 ${ }^{\mathrm{I}}$ & Neuron apoptotic process & 241.91 \\
\hline A0A1W2PQS2 & IQ motif and SEC7 domain-containing protein 2 (Fragment) ${ }^{\mathrm{D}}$ & $\begin{array}{l}\text { Structural component } \\
\text { of cytoskeleton }\end{array}$ & 385.21 \\
\hline Q16787 & Laminin subunit alpha- $3^{\mathrm{F}}$ & Cell adhesion & 282.82 \\
\hline Q16363 & Laminin subunit alpha- $4^{\mathrm{F}}$ & Cell adhesion & 215.34 \\
\hline Q2I0M4 & Leucine-rich repeat-containing protein $26^{\mathrm{C}}$ & Ion transport & 231.68 \\
\hline Q9Y2P4 & Long-chain fatty acid transport protein $6^{\mathrm{A}}$ & Lipid metabolism & 216.78 \\
\hline Q9Y561 & Low-density lipoprotein receptor-related protein $12^{\mathrm{A}}$ & Endocytosis & 243.95 \\
\hline 095711 & Lymphocyte antigen $86^{\mathrm{B}}$ & Innate immune response & 473.09 \\
\hline Q9BVV7 & $\begin{array}{l}\text { Mitochondrial import inner membrane } \\
\text { translocase subunit Tim } 21^{\mathrm{C}}\end{array}$ & Protein transport & 251.37 \\
\hline F8VYZ2 & Monocarboxylate transporter $2^{\mathrm{C}}$ & Transport & 306.67 \\
\hline 075970 & Multiple PDZ domain protein ${ }^{F}$ & Cell adhesion & 276.49 \\
\hline Q8IY17 & Neuropathy target esterase ${ }^{\mathrm{A}}$ & Lipid metabolism & 222.84 \\
\hline
\end{tabular}




\begin{tabular}{|c|c|c|c|}
\hline Accession & Description & Biologic process & Score \\
\hline Q8NH81 & Olfactory receptor $10 \mathrm{G} 6^{\mathrm{F}}$ & Sensory transduction & 252.13 \\
\hline P09131 & P3 protein ${ }^{\mathrm{C}}$ & Transport & 201.68 \\
\hline 095428 & Papilin ${ }^{G}$ & Protease inhibitor & 187.48 \\
\hline A6NIW5 & Peroxiredoxin 2_ isoform CRA_a ${ }^{\mathrm{J}}$ & Cell redox homeostasis & 776.51 \\
\hline P30041 & Peroxiredoxin- $6^{\mathrm{J}}$ & Antioxidant. Lipid metabolism & 1218.39 \\
\hline Q6IQ23 & Pleckstrin homology domain-containing family A member $7^{\mathrm{D}}$ & Cellular component & 270.31 \\
\hline Q3KNV8 & Polycomb group RING finger protein $3^{\mathrm{F}}$ & Transcription regulation & 192.63 \\
\hline Q5H9U9 & Probable ATP-dependent RNA helicase DDX60-like ${ }^{\mathrm{E}}$ & RNA-binding & 270.08 \\
\hline Q8IZL8 & Proline-_ glutamic acid- and leucine-rich protein $1 \mathrm{~F}$ & Transcription & 511.17 \\
\hline Q9H8V3 & Protein ECT2 ${ }^{\mathrm{H}}$ & Differentiation. Neurogenesis & 324.14 \\
\hline U3KQD2 & Protein GPR107 C & Protein transport & 186.68 \\
\hline Q9Y6F6 & Protein MRVI1 D & Membrane component & 270.56 \\
\hline Q8WXB1 & Protein N-lysine methyltransferase METTL21A ${ }^{\mathrm{F}}$ & Transferase & 236.44 \\
\hline A0A0A6YY99 & Protein TNFSF12-TNFSF13 ${ }^{\text {в }}$ & Immune response & 490.49 \\
\hline 094855 & Protein transport protein Sec24D c & Protein transport & 271.08 \\
\hline Q69YN4 & Protein virilizer homolog $\mathrm{E}$ & mRNA processing & 321.84 \\
\hline A8MUN3 & Putative uncharacterized protein ENSP00000381830 L & Unknown & 672.41 \\
\hline Q96D71 & RalBP1-associated Eps domain-containing protein $1 \mathrm{~K}$ & Calcium binding & 277.02 \\
\hline Q92619 & Rho GTPase-activating protein $45^{\mathrm{F}}$ & Intracellular signal transduction & 290.3 \\
\hline E5RI70 & Rho GTPase-activating protein 7 (Fragment) ${ }^{\mathrm{I}}$ & Apoptosis process & 1145.15 \\
\hline Q9NRP7 & Serine/threonine-protein kinase $36^{\mathrm{A}}$ & Kinase activity & 197.99 \\
\hline Q96BR1 & Serine/threonine-protein kinase Sgk3 A & Kinase activity & 163.05 \\
\hline P30154 & $\begin{array}{l}\text { Serine/threonine-protein phosphatase } 2 \mathrm{~A} 65 \\
\mathrm{kDa} \text { regulatory subunit A beta isoform }{ }^{\mathrm{I}}\end{array}$ & Apoptotic process & 273.47 \\
\hline Q8TE82 & SH3 domain and tetratricopeptide repeat-containing protein $1{ }^{\mathrm{L}}$ & Unknown & 248.71 \\
\hline Q8TCT6 & Signal peptide peptidase-like 3 A & $\mathrm{T}$ cell receptor signaling pathway & 203.96 \\
\hline 094813 & Slit homolog 2 protein ${ }^{\mathrm{H}}$ & Differentiation. Neurogenesis & 187.71 \\
\hline P05023 & Sodium/potassium-transporting ATPase subunit alpha- $1^{\mathrm{K}}$ & Ion transport & 328.76 \\
\hline Q8WUM9 & Sodium-dependent phosphate transporter $1^{\mathrm{K}}$ & Phosphate ion transport & 571.51 \\
\hline P02549 & Spectrin alpha chain_erythrocytic $1^{D}$ & $\begin{array}{l}\text { Structural component } \\
\text { of cytoskeleton }\end{array}$ & 335.76 \\
\hline A0A087WXB8 & $\begin{array}{l}\text { ST3 beta-galactoside alpha-2_3- } \\
\text { sialyltransferase 6_ isoform CRA_b }{ }^{\text {A }}\end{array}$ & Protein glycosylation & 277.21 \\
\hline Q8IVG5 & Sterile alpha motif domain-containing protein 9-like ${ }^{G}$ & Regulation of growth factor & 456.51 \\
\hline P57105 & Synaptojanin-2-binding protein ${ }^{\mathrm{G}}$ & Regulation of growth factor & 169.06 \\
\hline Q86Y82 & Syntaxin-12 c & Protein transport & 371.79 \\
\hline Q6PGP7 & Tetratricopeptide repeat protein $37^{\mathrm{A}}$ & Catabolic process & 262.47 \\
\hline A0A0U1RQW3 & Three prime repair exonuclease 1 _ isoform CRA_a ${ }^{\mathrm{E}}$ & DNA damage checkpoint & 636.8 \\
\hline I3L3T4 & TOM1-like protein $1^{\mathrm{C}}$ & Intracellular protein transport & 194.25 \\
\hline 075204 & Transmembrane protein $127^{\mathrm{D}}$ & Endosome organization & 791.15 \\
\hline Q14CX5 & Transmembrane protein $180^{\mathrm{D}}$ & Membrane component & 341.01 \\
\hline
\end{tabular}




\begin{tabular}{|c|c|c|c|}
\hline Accession & Description & Biologic process & Score \\
\hline Q9NX78 & Transmembrane protein $260^{\mathrm{D}}$ & Membrane component & 121.58 \\
\hline Q9BTW9 & Tubulin-specific chaperone $\mathrm{D}^{\mathrm{D}}$ & $\begin{array}{l}\text { Microtubule cytoskeleton } \\
\text { organization }\end{array}$ & 328.09 \\
\hline Q2QBA2 & $\begin{array}{l}\text { Tumor necrosis factor (Ligand) superfamily } \\
\text { member } 13 \text { transcript variant delta }{ }^{B}\end{array}$ & Immune response & 490.49 \\
\hline 075888 & Tumor necrosis factor ligand superfamily member $13 \mathrm{~B}$ & Immune response & 490.49 \\
\hline Q9Y274 & Type 2 lactosamine alpha-2_3-sialyltransferase ${ }^{\mathrm{A}}$ & Metabolic process & 277.21 \\
\hline A0A0B4J269 & Uncharacterized protein ${ }^{\mathrm{H}}$ & Neuron differentiation & 526.49 \\
\hline S4R451 & WD repeat-containing protein $11^{\mathrm{A}}$ & Signaling pathway to ciliogenesis & 385.34 \\
\hline Q9UII5 & Zinc finger protein $107^{\mathrm{F}}$ & Transcription regulation & 162.73 \\
\hline Q8NHY6 & Zinc finger protein 28 homolog $\mathrm{F}$ & Transcription regulation & 415.19 \\
\hline F8WAL3 & Zinc finger protein $528{ }^{\mathrm{F}}$ & Transcription regulation & 269.74 \\
\hline Q86YE8 & Zinc finger protein $573^{\mathrm{F}}$ & Transcription regulation & 246.76 \\
\hline Q03923 & Zinc finger protein $85^{\mathrm{F}}$ & Transcription regulation & 289.34 \\
\hline \multicolumn{4}{|c|}{ Necrotic pulp } \\
\hline P31946 & 14-3-3 protein beta/alpha ${ }^{\mathrm{B}}$ & Host-virus interaction & 731.1 \\
\hline Q6N063 & $\begin{array}{l}\text { 2-oxoglutarate and iron-dependent oxygenase } \\
\text { domain-containing protein } 2^{\mathrm{J}}\end{array}$ & Oxidoreductase activity & 350.12 \\
\hline Q86U10 & 60 kDa lysophospholipase ${ }^{\mathrm{A}}$ & Lipid metabolism & 653.91 \\
\hline E9PNY0 & Adenine DNA glycosylase ${ }^{\mathrm{E}}$ & DNA repair & 1337.74 \\
\hline P55196 & Afadin ${ }^{\mathrm{F}}$ & Cell adhesion & 546.31 \\
\hline P02763 & Alpha-1-acid glycoprotein $1^{\text {B }}$ & Regulation of immune system & 588.98 \\
\hline P04217 & Alpha-1B-glycoprotein ${ }^{\text {B }}$ & Neutrophil degranulation & 418.04 \\
\hline P01019 & Angiotensinogen ${ }^{\mathrm{G}}$ & Growth factor activity & 772.78 \\
\hline Q6ZTN6 & Ankyrin repeat domain-containing protein 13D ${ }^{\mathrm{F}}$ & Ubiquitin-binding protein & 491.4 \\
\hline K7EL63 & Ankyrin repeat domain-containing protein 29 (Fragment) ${ }^{\mathrm{L}}$ & Unknown & 358.5 \\
\hline C9JP59 & $\begin{array}{l}\text { Ankyrin repeat_SAM and basic leucine zipper } \\
\text { domain-containing protein } 1 \text { (Fragment) }{ }^{\mathrm{L}}\end{array}$ & Unknown & 859.6 \\
\hline Q01484 & Ankyrin-2 ${ }^{\mathrm{C}}$ & Protein transport & 58.02 \\
\hline Q9Y2F9 & $\mathrm{BTB} / \mathrm{POZ}$ domain-containing protein $3{ }^{\mathrm{H}}$ & Neurogenesis & 645.18 \\
\hline Q9BXU9 & Calcium-binding protein $8{ }^{\mathrm{K}}$ & Calcium ion binding & 451.01 \\
\hline B4E1Z4 & $\begin{array}{l}\text { cDNA FLJ55673_highly similar to } \\
\text { Complement factor B (EC 3.4.21.47) }{ }^{\mathrm{B}}\end{array}$ & Complement activation & 503.52 \\
\hline A0A087X2B6 & Cell cycle and apoptosis regulator protein $2^{\mathrm{I}}$ & Regulation of apoptotic process & 704.06 \\
\hline A6PVI9 & Centrosomal protein $250 \mathrm{kDa}{ }^{\mathrm{G}}$ & Cell cycle & 461.65 \\
\hline Q9BV73 & Centrosome-associated protein CEP250 G & Cell cycle & 490.84 \\
\hline P00450 & Ceruloplasmin ${ }^{\mathrm{K}}$ & Ion transport & 161 \\
\hline H3BN91 & C-Jun-amino-terminal kinase-interacting protein 3 (Fragment) ${ }^{\mathrm{H}}$ & Axon regeneration & 327.76 \\
\hline P01024 & Complement C3 A & Complement pathway & 788.64 \\
\hline P00751 & Complement factor B ${ }^{\mathrm{B}}$ & Innate immunity & 503.52 \\
\hline 015315 & DNA repair protein $\mathrm{RAD} 51$ homolog $2^{\mathrm{E}}$ & DNA repair & 292.13 \\
\hline Q7L591 & Docking protein $3 \mathrm{~F}$ & Signal transduction & 282.57 \\
\hline
\end{tabular}




\begin{tabular}{|c|c|c|c|}
\hline Accession & Description & Biologic process & Score \\
\hline Q9NRD9 & Dual oxidase $1^{\mathrm{J}}$ & Oxidoreductase & 1227.04 \\
\hline QOPNE2 & Elongator complex protein $6^{\mathrm{F}}$ & Transcription regulation & 406.73 \\
\hline E7EU71 & Ephrin type-A receptor $6^{\mathrm{D}}$ & Membrane component & 466.19 \\
\hline Q9NRG7 & Epimerase family protein SDR39U1 $\mathrm{J}$ & Oxidoreductase & 346.17 \\
\hline I6L9I8 & EPN3 protein ${ }^{\mathrm{L}}$ & Unknown & 628.04 \\
\hline Q9H201 & Epsin-3 $\mathrm{F}$ & Lipid-binding & 650.19 \\
\hline C9JLC0 & F-box/SPRY domain-containing protein $1^{\mathrm{H}}$ & Neurogenesis & 326.5 \\
\hline P02675 & Fibrinogen beta chain ${ }^{B}$ & Innate immunity & 518.5 \\
\hline P00739 & Haptoglobin-related protein ${ }^{\mathrm{I}}$ & Regulation of cell death & 1026.1 \\
\hline A0A0B4J1V2 & Immunoglobulin heavy variable $2-26^{\text {B }}$ & Adaptive immunity & 663.4 \\
\hline P01834 & Immunoglobulin kappa constant ${ }^{B}$ & Adaptive immunity & 3257.26 \\
\hline P01619 & Immunoglobulin kappa variable $3-20^{\mathrm{B}}$ & Adaptive immunity & 613.37 \\
\hline POCG04 & Immunoglobulin lambda constant $1^{\mathrm{B}}$ & Adaptive immunity & 4803.8 \\
\hline PODOY2 & Immunoglobulin lambda constant 2 B & Adaptive immunity & 4803.8 \\
\hline PODOY3 & Immunoglobulin lambda constant 3 B & Adaptive immunity & 2697.85 \\
\hline P0CF74 & Immunoglobulin lambda constant $6^{\mathrm{B}}$ & Adaptive immunity & 1652.51 \\
\hline A0M8Q6 & Immunoglobulin lambda constant 7 в & Adaptive immunity & 402.02 \\
\hline B9A064 & Immunoglobulin lambda-like polypeptide 5 в & Innate immune response & 4803.8 \\
\hline Q53G59 & Kelch-like protein $12^{\mathrm{A}}$ & Ubl conjugation pathway & 237.11 \\
\hline P02788 & Lactotransferrin ${ }^{\mathrm{K}}$ & Ion transport & 256.65 \\
\hline Q6ZSS7 & Major facilitator superfamily domain-containing protein $6^{\mathrm{D}}$ & Membrane component & 148.16 \\
\hline B5MC10 & MpV17 mitochondrial inner membrane protein isoform $2^{\mathrm{J}}$ & Regulation of reactive oxygen & 563.58 \\
\hline E9PK80 & NAD-dependent protein deacetylase ${ }^{A}$ & Catalytic activity & 1042.07 \\
\hline Q9NTG7 & NAD-dependent protein deacetylase sirtuin-3_ mitochondrial A & Catalytic activity & 1060.08 \\
\hline Q9UBB6 & Neurochondrin ${ }^{\mathrm{F}}$ & Signal transduction & 490.42 \\
\hline P59665 & Neutrophil defensin 1 в & Antiviral defense & 7785.6 \\
\hline P59666 & Neutrophil defensin 3 в & Antiviral defense & 1433.54 \\
\hline P08246 & Neutrophil elastase ${ }^{A}$ & Catalytic activity & 614.34 \\
\hline Q15155 & Nodal modulator $1 \mathrm{D}$ & Membrane component & 523.61 \\
\hline Q5JPE7 & Nodal modulator $2 \mathrm{D}$ & Membrane component & 45.57 \\
\hline P69849 & Nodal modulator $3 \mathrm{D}$ & Membrane component & 533.01 \\
\hline A0A0J9YWI0 & Peroxisomal 2_4-dienoyl-CoA reductase (Fragment) ${ }^{\mathrm{J}}$ & Oxidoreductase & 424.99 \\
\hline P27986 & Phosphatidylinositol 3-kinase regulatory subunit alpha I & Regulation of apoptotic process & 462.89 \\
\hline 000443 & $\begin{array}{l}\text { Phosphatidylinositol 4-phosphate 3-kinase } \\
\text { C2 domain-containing subunit alpha c }\end{array}$ & Endocytosis & 586 \\
\hline A0A0U1RQS1 & Probable global transcription activator SNF2L2 (Fragment) ${ }^{\mathrm{H}}$ & Neurogenesis & 986.63 \\
\hline Q9BVM2 & Protein DPCD ${ }^{D}$ & Formation of ciliated cells & 225.08 \\
\hline С9КоСо & Protein FAM71F2 L & Unknown & 1745.9 \\
\hline P06702 & Protein S100-A9 I & Apoptosis & 4809.99 \\
\hline Q96I85 & Putative uncharacterized protein C14orf144 L & Unknown & 1071.1 \\
\hline
\end{tabular}




\begin{tabular}{|c|c|c|c|}
\hline Accession & Description & Biologic process & Score \\
\hline Q86TS7 & Putative UPF0730 protein encoded by LINC00643 L & Unknown & 506.3 \\
\hline Q9UHV5 & Rap guanine nucleotide exchange factor-like $1^{\mathrm{H}}$ & Nervous system development & 657.95 \\
\hline P52565 & Rho GDP-dissociation inhibitor $1^{\mathrm{I}}$ & Regulation of apoptotic process & 241.48 \\
\hline J3KPQ4 & Rho GTPase activating protein 9_ isoform CRA_a ${ }^{F}$ & Signal transduction & 421.35 \\
\hline Q9BRR9 & Rho GTPase-activating protein $9^{\mathrm{F}}$ & Signal transduction & 421.35 \\
\hline 015393 & Transmembrane protease serine $2^{\mathrm{A}}$ & Catalytic activity & 300.54 \\
\hline A0A1W2PQJ5 & Uncharacterized protein ${ }^{\mathrm{L}}$ & Unknown & 331.97 \\
\hline H0Y8H3 & Uncharacterized protein C3orf67 (Fragment) ${ }^{\mathrm{L}}$ & Unknown & 864.21 \\
\hline P02774 & Vitamin D-binding protein ${ }^{c}$ & Transport & 470.82 \\
\hline E9PNL3 & V-type proton ATPase $21 \mathrm{kDa}$ proteolipid subunit ${ }^{\mathrm{K}}$ & Ion transport & 222.07 \\
\hline
\end{tabular}

Proteins were classified according to Uniprot database: A - Metabolism and energy pathways; B - Immune response; C - Transport; D - Structure; E - DNA/RNA regulation and repair; F - Cell communication and signal transduction; G - Cell growth and/or maintenance; H- Differentiation of neural cells; I- Apoptosis; J- Stress response; K- Ions regulation and binding; L- Unknown.

The immunoinflammatory response is intended to restore the structural and functional integrity of the injured tissue by eliminating irritants as quickly as possible (17). Indicating the activity of the immune response in inflamed
pulp, three immunoglobulin isoforms were present in greater amounts in the inflamed tissue than in the healthy tissue samples. The increase of Nuclear mitotic apparatus protein indicates cell division, probably related to the proliferation of immunoinflammatory cells.

The release of reactive oxygen species (ROS) by 
disintegrated neutrophils and macrophages within the pulp tissue might damage these tissues. ROS are mandatory byproducts of the metabolic activities of living aerobic organisms (18). Removal of ROS is done by peroxiredoxins - a family of antioxidant proteins that catalyze these substances. Two isoforms of Peroxiredoxins were upregulated in the inflamed pulp group when compared to the normal tissue, which are responsible for the protection of cellular components against oxidative damage. They are involved in processes such as cell proliferation and differentiation, protection of free radical-sensitive proteins, hemoglobin metabolism and intracellular signaling (19).

Throughout the inflammatory process maintained by the aggressive agent, damage to the pulp tissue occurs, with consequent cell death and destruction of the extracellular matrix. The down-regulation of 17 isoforms of Tubulin in the inflamed pulp group shows the disorganization and destruction of the structural portion of the cell in front of this process (20). Neurofilament proteins, such as Alphainternexin and Neurofilament medium polypeptide were also down-regulated, which could be predicted due to the intense inflammation present in irreversible pulpitis. Some other proteins were also found with a high level expression in inflamed pulpal tissue, most of them participating in biological processes related to transport, and metabolism and energy pathways.

As a result of the evolution of the inflammatory process of the pulp, the vital functions of the pulp are compromised, followed by hypoxia and tissue necrosis. In this context, there are also changes in blood microcirculation that led to reduced pulp blood flow, explaining the down-regulation of hemoglobin in the necrotic pulp group, when compared with the inflamed one (21). The down-regulation of 4 isoforms of actins show that the mortification process of the pulp tissue leads to destruction of the cytoskeleton and rupture of actin microfilaments. Actin is a protein involved in structuring the cytoskeleton. The actin microfilaments participate in the generation of forces and cell adhesion, stabilizing the cell and determining the shape of the plasma membrane (22).

Among the proteins up-regulated in the necrotic group, serum albumin, albumin, immunoglobulin, and alpha-2macroglobulin were found. Proteins derived from albumin and serum albumin are constituents of fluids and exudates that infiltrate the apical and lateral foramen of the root canal. Albumin and immunoglobulins may be related to the immune response as they participate in reducing the diffusion of antigens when they adhere to the dentinal tubules (23).

Immunity-related proteins, such as immunoglobulins and protease inhibitors, involved in antigen presentation, defense cell activation and stress response can be identified in necrotic pulps, suggesting that host cells react to root canal system infections (24). One of the proteins found in high level in this group, Alpha-2-macroglobulin ( $\alpha 2 \mathrm{M}$ ), protects the body against bacterial endotoxins, regulating apoptosis and inhibiting the generation of hydrogen peroxide. In addition, $\alpha 2 \mathrm{M}$ can be used as a biomarker for the diagnosis and prognosis of various diseases (25).

The most recurrent biological processes found in normal pulp tissue provide tissue balance, including maintenance, renewal and energy supply for cellular interaction. In the inflamed pulp group, there was an increase in the percentage of proteins involved in the regulation and repair of DNA / RNA in order to allow cell viability. This may have occurred due to the damage suffered by the cells of the pulp tissue during the inflammatory process. Meanwhile, the increase of proteins associated with metabolism and energetic pathways is directly related to the greater cellular activity for the elimination of the aggressive agent. Moreover, samples representing the infected pulp had a higher percentage of proteins with biological function related to the immune response, which was also described by Provenzano et al. (24), revealing the presence of viable host cells at the site of infection. These results contribute to the understanding of the complex pathogen-host relationship, the host's antimicrobial strategies to fight the infections and shed light into the pathogenesis of the disease.

The present study was the first report to analyze both qualitative and quantitatively proteins differently expressed in normal, inflamed and necrotic pulp, thus providing important data that might not only contribute to the understanding of the complex pathogen-host relationship involved in the progression of pulp diseases, but also to direct future researches. Moreover, the present study reported higher levels of proteins that are considered constitutively produced and ideally should be constant such as beta actin, Glyceraldehyde-3 phosphate dehydrogenase, macroglobulin and tubulin. Therefore, future studies using quantitative methods such as Real time-PCR and Western Blotting analysis should avoid targeting such genes/proteins as reference when analyzing samples related to pathosis of the pulp.

In conclusion, this proteomic analysis showed quantitative differences in protein expression in different types of pulp conditions and revealed that pulp inflammation induced a high-level expression of proteins related to cellular communication and signal transduction. Nevertheless, with the progression to pulp necrosis, the proteins were associated with immune response.

\section{Resumo}

Este estudo teve como objetivo comparar quantitativamente a diferença da expressão de proteínas na progressão da patogênese pulpar, bem 
como descrever as funções biológicas das proteínas identificadas no tecido pulpar. As amostras foram obtidas de seis pacientes atendidos na Faculdade de Odontologia de Araçatuba e divididas em três grupos: polpa normal - dentes extraidos por indicação ortodôntica; polpa inflamada e polpa necrótica - pacientes diagnosticados com pulpite irreversivel e periodontite apical crônica, respectivamente. Após o preparo proteômico prévio, as amostras de polpa dentária foram processadas para análise proteômica quantitativa livre de marcadores em um sistema nanoACQUITY UPLC-Xevo QTof MS. A diferença de expressão entre os grupos foi calculada usando o software Protein Lynx Global Service através do algoritmo de Monte Carlo. Um total de 465 proteinas humanas foram identificadas em todos os grupos. As proteínas mais expressas no grupo polpa inflamada em relação ao grupo polpa normal foram hemoglobinas, peroxirredoxinas e imunoglobulinas, enquanto as menos expressas foram as tubulinas. Os níveis de expressão de albuminas, imunoglobulinas e alfa-2-macroglobulina foram maiores no grupo polpa necrótica do que no grupo de polpa inflamada. Quanto à análise qualitativa, as funções proteicas mais prevalentes no grupo polpa normal foram vias metabólicase energéticas; no grupo polpa inflamada: comunicação celular e transdução de sinal; e regulação e reparo de DNA / RNA, enquanto no grupo polpa necrótica as proteinas foram associadas à resposta imune. Assim, a análise proteômica mostrou diferenças quantitativas e qualitativas na expressão de proteinas em diferentes tipos de condições pulpares.

\section{Acknowledgements}

We are thankful to the Laboratory of Biochemistry from the Bauru School of Dentistry, University of São Paulo. This study was supported by the Brazilian agencies FAPESP (2018/18741-0, 2018/08282-9, 2019/14995-0), CNPq (169451/2017-8) and CAPES (Finance code 001).

\section{References}

1. Ricucci D, Siqueira JF Jr. Biofilms and apical periodontitis: study of prevalence and association with clinical and histopathologic findings. J Endod 2010;36:1277-1288.

2. Siqueira JF Jr, Rôças IN. Community as the unit of pathogenicity: an emerging concept as to the microbial pathogenesis of apical periodontitis. Oral Surg Oral Med Oral Pathol Oral Radiol Endod 2009; 107:870-878.

3. Jacinto RC, Gomes BP, Ferraz CC, Zaia AA, Filho FJ. Microbiological analysis of infected root canals from symptomatic and asymptomatic teeth with periapical periodontitis and the antimicrobial susceptibility of some isolated anaerobic bacteria. Oral Microbiology and Immunology 2003;18:285-292.

4. Wilkins MR, Pasquali C, Appel RD, Ou K, Golaz O, Sanchez JC et al. From proteins to proteomes: large scale protein identification by twodimensional electrophoresis and amino acid analysis. Biotechnology 1996;14:61-65.

5. Macarthur DJ, Jacques NA. Proteome analysis of oral pathogens. J Dent Res 2003;82:870-876.

6. Mirrashidi KM, Elwell CA, Verschueren E, Johnson JR, Frando A, Von Dollen J et al. Global Mapping of the Inc-Human Interactome Reveals that Retromer Restricts Chlamydia Infection. Cell Host Microbe 2015;18:109-121.
7. Motoyama A, Yates JR 3rd. Multidimensional LC separations in shotgun proteomics. Analyt Chem 2008;80:7187-7193.

8. Nikolov M, Schmidt C, Urlaub H. Quantitative mass spectrometry-based proteomics: an overview. Methods Mol Biol 2012;893:85-100.

9. Nandakumar R, Madayiputhiya N, Fouad AF. Proteomic analysis of endodontic infections by liquid chromatography-tandem mass spectrometry. Oral Microbiol Immunol 2009;24:347-352.

10. Alfenas CF, Mendes TAO, Ramos HJO, Bruckner FP, Antunes HS, Rôças IN et al. Human Exoproteome in Acute Apical Abscesses. J Endod. 2017;43:1479-1485.

11. Francisco PA, Delboni MG, Lima AR, Xiao Y, Siqueira WL, Gomes B. Proteomic profile of root canal contents in teeth with post-treatment endodontic disease. Int Endod J 2019;52:451-460.

12. Ventura T, Cassiano LPS, Souza ESCM, Taira EA, Leite AL, Rios D et al. The proteomic profile of the acquired enamel pellicle according to its location in the dental arches. Arch Oral Biol 2017;79:20-29.

13. Eckhardt A, Jagr M, Pataridis S, Miksik I. Proteomic analysis of human tooth pulp: proteomics of human tooth. J Endod 2014;40:1961-1966.

14. Murad AM, Rech EL. NanoUPLC-MSE proteomic data assessment of soybean seeds using the Uniprot database. BMC Biotechnology 2012; 12:82.

15. Malka R, Delgado FF, Manalis SR, Higgins JM. In vivo volume and hemoglobin dynamics of human red blood cells. PLoS Comput Biol 2014; 10:e1003839.

16. Heyeraas KJ, Kvinnsland. Tissue pressure and blood flow in pulpal inflammation. Oral Crit Rev Biol Med 1992;88:393-401.

17. Speer ML, Madonia JV, Heuer MA. Quantitative evaluation of the immunocompetence of the dental pulp. J Endod 1977;3:418-423.

18. Rhee SG. Overview on Peroxiredoxin. Mol Cells 2016;39:1-5.

19. Fisher $A B$. Peroxiredoxin 6: a bifunctional enzyme with glutathione peroxidase and phospholipase A (2) activities. Antioxid Redox Signal 2011;15:831-844.

20. Monteiro MR, Kandratavicius L, Leite JP. The role of cytoskeleton proteins in normal cell physiology and in pathological conditions. J. Epilepsy Clin. Neurophysiol 2011;17:17-23.

21. Abbott PV, Yu C. A clinical classification of the status of the pulp and the root canal system. Aust Dent J 2007;52:S17-31.

22. Taniguchi LU, Caldini EG, Velasco IT, Negri EM. Cytoskeleton and mechanotransduction in the pathophysiology of ventilator-induced lung injury. J. Bras. Pneumol 2010;36:363-371.

23. Hahn $\mathrm{CL}$, Best $\mathrm{AM}$. The pulpal origin of immunoglobulins in dentin beneath caries: an immunohistochemical study. J Endod 2006;32:178182.

24. Provenzano JC, Siqueira JF Jr, Rôças IN, Domingues RR, Paes Leme $A F$, Silva MR. Metaproteome analysis of endodontic infections in association with different clinical conditions. PLoS One 2013;8:e76108.

25. Rehman AA, Ahsan H, Khan FH. Alpha-2-Macroglobulin: a physiological guardian. J Cell Physiol 2013;228:1665-1675.

Received September 19, 2019 Accepted December 17, 2019 